\title{
Big wheel keeps on turning: apoptosome regulation and its role in chemoresistance
}

\author{
B Fadeel $^{*, 1}$, A Ottosson $^{1}$ and S Pervaiz ${ }^{2}$
}

Apoptosis, a form of programmed cell death, enables organisms to maintain tissue homeostasis through deletion of extraneous cells and also serves as a means to eliminate potentially harmful cells. Numerous stress signals have been shown to engage the intrinsic pathway of apoptosis, with the release from mitochondria of proapoptotic factors such as cytochrome $c$ and the subsequent formation of a cytosolic complex between apoptotic protease-activating factor-1 (Apaf-1) and procaspase-9, known as the apoptosome. Recent studies have led to the identification of an array of factors that control the formation and activation of the apoptosome under physiological conditions. Moreover, deregulation of apoptosome function has been documented in various forms of human cancer, and may play a role in both carcinogenesis and chemoresistance. We discuss how the apoptosome is regulated in normal and disease states, and how targeting of apoptosome-dependent, post-mitochondrial stages of apoptosis may serve as a rational approach to cancer treatment.

Cell Death and Differentiation (2008) 15, 443-452; doi:10.1038/sj.cdd.4402265; published online 2 November 2007

Apoptosis is a process of controlled cell deletion that plays a fundamental role in multicellular organisms. ${ }^{1}$ Disruption of the normal orderly demise of cells through suppression or inadvertent activation of the apoptosis machinery contributes to a number of human diseases including cancer, autoimmune conditions, and neurodegenerative disorders. ${ }^{2}$ An increased understanding of the signaling pathways that govern the execution of apoptosis may thus yield novel targets for rational therapeutic intervention in a wide range of human maladies.

\section{Setting the Scene: Intrinsic and Extrinsic Apoptosis Signaling}

The apoptotic program is executed by a family of cysteinedependent proteases known as caspases, which are activated in a proteolytic cascade, resulting ultimately in the dismantling of the cell and the rapid clearance of the cell corpse by neighboring phagocytes. ${ }^{3}$ There are two major pathways of caspase activation in mammalian cells: the extrinsic or receptor-mediated pathway and the intrinsic or mitochondria-dependent pathway (Figure 1). The extrinsic pathway involves the binding of extracellular death ligands, such as Fas ligand or tumor necrosis factor (TNF)-related apoptosis-inducing ligand (TRAIL), to their corresponding cell-surface receptors, followed by recruitment of initiator caspases (procaspase-8 and/or procaspase-10) in a multiprotein complex at the plasma membrane, and the subsequent cleavage and activation of downstream effector caspases, including procaspase-3. The receptor-mediated pathway is of particular importance for immune homeostasis and immune function. ${ }^{4}$ The intrinsic pathway, which is the main focus of the current review, is characterized by activation and permeabilization of mitochondria, with the release of cytochrome $c$ and other proapoptotic molecules from these organelles into the cytosol. Cytochrome $c$ serves as a cofactor for apoptotic protease-activating factor-1 (Apaf-1) oligomerization and the activation of procaspase- 9 , an initiator caspase. This molecular platform, known as the apoptosome, then activates downstream caspases, including procaspase-3, eventually leading to death of the cell. ${ }^{5}$ Hence, both pathways involve a cascade of proteolytic activity within the cell, either downstream of the plasma membrane or mitochondria, and converge on the activation of the same effector caspases that are responsible for the final execution of the cell. Moreover, cross talk between these two pathways occurs. Hence, caspase-8, an initiator caspase in the extrinsic pathway, can cleave and activate the proapoptotic Bcl-2 family member, Bid, to promote cytochrome $c$ release, thus serving to amplify the initial death stimulus. ${ }^{6,7}$ Recent studies from several laboratories have provided further evidence of caspase activation upstream of the disruption of

\footnotetext{
${ }^{1}$ Cell Death Research Group, Division of Biochemical Toxicology, Institute of Environmental Medicine, Karolinska Institutet, Stockholm, Sweden and ${ }^{2}$ Department of Physiology, National University of Singapore, Singapore

${ }^{*}$ Corresponding author: B Fadeel, Cell Death Research Group, Division of Biochemical Toxicology, Institute of Environmental Medicine, Karolinska Institutet, Stockholm 171 77, Sweden. Tel: + 468524877 37; Fax: + 4683438 49; E-mail: bengt.fadeel@ki.se

Keywords: apoptosis; apoptosome; cancer; caspase; chemoresistance

Abbreviations: AIF, apoptosis-inducing factor; Apaf-1, apoptotic protease-activating factor-1; B-CLL, B-cell chronic lymphocytic leukemia; $\mathrm{BH}, \mathrm{Bcl}-2$ homology domain; CARD, caspase recruitment domain; CED, cell death abnormal; CNS, central nervous system; CPS, CED-3 protease suppressor; DARK, Drosophila Apaf-1-related killer; DD, death domain; DISC, death-inducing signaling complex; EGL, egg laying-defective; HCA66, hepatocellular carcinoma antigen 66; Hsp, heat shock protein; NALP1, [NACHT, LRR and PYD (pyrin domain)-containing protein-1]; NOD, nucleotide oligomerization domain; PHAP, putative HLA-DR-associated protein; PIDD, p53-induced protein with death domain; ProT, prothymosin- $\alpha$; Smac, second mitochondrial activator of caspases; TNF, tumor necrosis factor; TRAIL, TNF-related apoptosis-inducing ligand; WAH, worm AIF homolog; XIAP, X-linked inhibitor of apoptosis protein

Received 24.5.07; revised 20.8.07; accepted 01.10.07; Edited by RA Knight; published online 02.11.07
} 


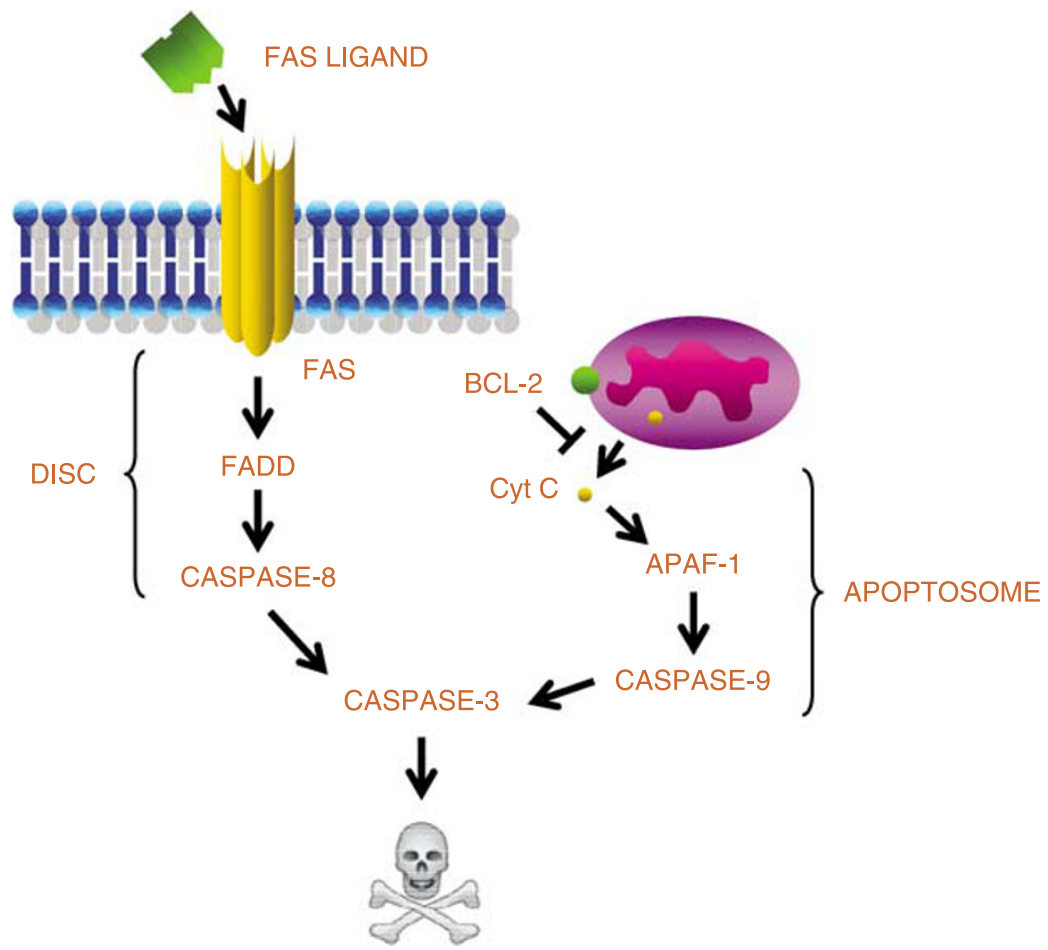

Figure 1 Extrinsic and intrinsic apoptosis pathways. There are two major pathways of caspase activation in mammalian cells: the extrinsic or death receptor-mediated pathway, and the intrinsic or mitochondria-dependent pathway. The Fas-Fas ligand pathway shown in this cartoon is the most well-characterized extrinsic pathway to date (DISC, death-inducing signaling complex). Both signaling pathways converge on the activation of the so-called executioner caspases, including caspase-3, which are responsible for the rapid dismantling of the cell, followed by the removal of the cell corpse by phagocytes. Recent studies also suggest that caspase activation may occur upstream of mitochondria in the intrinsic pathway; ${ }^{8}$ in this scenario, the mitochondrion with its arsenal of proapoptotic molecules (including cytochrome $c$ ) may simply serve to amplify the initial apoptotic signal

mitochondria. For example, genotoxic stress has been shown to activate procaspase-2, leading to translocation of the proapoptotic protein Bax to mitochondria and release of cytochrome $c$ into the cytosol, with the activation of the

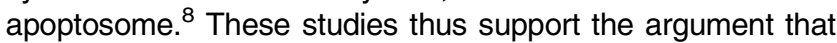
mitochondria exist as amplifiers of the caspase cascade in response to diverse cell death stimuli rather than as initiators of caspase activation.

Apoptosis resistance is considered as one of the cardinal features of all human cancers. ${ }^{9}$ In other words, specific defects in the apoptotic pathways described above can contribute to tumor development and progression. Furthermore, most conventional anticancer modalities, including chemotherapeutic drugs and irradiation treatment, are thought to induce cell death of cancer cells through activation of the mitochondria-dependent pathway of apoptosis. ${ }^{10}$ Therefore, it follows that cancer resistance to treatment may result from alterations in the normal pathway of apoptosomedependent apoptosis. This review will focus on the regulation of apoptosome formation and activation in normal and disease states, and the role of apoptosome dysfunction in carcinogenesis and chemoresistance.

\section{Conservation of Apoptotic Paradigms from Worm to Fruit Fly to Man}

Pioneering genetic studies have identified four genes that act in concert to control the onset of apoptosis in the microscopic soil-dwelling roundworm Caenorhabditis elegans, a favorite model of cell death aficionados. ${ }^{11}$ Cell death abnormal-3 (CED-3), the nematode killer protease, is required for somatic programmed cell death in the worm, and is activated by the adaptor protein, CED-4. The action of CED-4 is, in turn, regulated by CED- 9 through a mechanism of direct sequestration: CED-9, which is tethered to mitochondria, binds CED-4 and prevents it from activating CED-3 until a death signal induces egg laying-defective-1 (EGL-1). EGL-1, a homolog of the mammalian $\mathrm{Bcl}-2$ homology domain 3 (BH3)-only proteins, then displaces CED-9, thereby allowing CED-4 to activate CED-3. Through the interplay of CED-3, CED-4, CED-9, and EGL-1, a specific number of cells are killed at precise times during development of the worm and in precise locations.

Horvitz and co-workers ${ }^{12}$ demonstrated that CED-3 is a member of the caspase family of proteases, and this discovery was instrumental in identifying a role for mammalian caspases in the regulation of programmed cell death. Moreover, the cloning of the gene encoding CED-9 revealed that this protein is similar to the product of the human protooncogene $\mathrm{Bcl}-2$ (reference Hengartner and Horvitz ${ }^{13}$ ), which was shown by other investigators to possess antiapoptotic functions. ${ }^{14,15}$ The observation that human Bcl-2 could also block programmed cell death in $C$. elegans and could substitute for CED-9 in the worm ${ }^{16}$ provided compelling evidence that the cell death pathway is conserved between species. Seminal biochemical fractionation and characteriza- 
tion studies performed by Wang and colleagues then identified Apaf-1 as a mammalian homolog of CED-4 (reference Zou et al. $^{17}$ ), and subsequent studies from the same group showed that Apaf-1, in the presence of cytochrome $c$ and dATP, oligomerizes to form an apoptosome, ${ }^{18}$ a platform for caspase activation. Moreover, the demonstration that $\mathrm{Bcl}-2$ can prevent release from mitochondria of cytochrome $c$, the cofactor for Apaf-1-dependent caspase activation, ${ }^{19,20}$ further supports the view that the overall framework of programmed cell death is conserved from worm to man.

CED-4 can function both as an activator and inhibitor of cell death. These opposing activities appear to result from two protein isoforms of CED-4, termed CED-4S and CED-4L, encoded by alternatively spliced transcripts. ${ }^{21}$ How the CED$4 \mathrm{~L}$ protein inhibits programmed cell death remains unknown; however, the simplest model is that CED-4L functions as an interfering dominant-negative form of the CED-4 protein. Apaf-1 also exists in several distinct splice forms, ${ }^{22}$ each containing an $\mathrm{N}$-terminal caspase recruitment domain (CARD), a central CED-4-like domain, and 13 or 14 WD40 repeats to which cytochrome $c$ binds (Figure 2). Unlike Apaf-1, CED-4 does not have WD40 domains and hence does not bind cytochrome $c$. Moreover, unlike CED-4, Apaf-1 is not localized to mitochondria and does not bind $\mathrm{Bcl}-2$ (reference Hausmann et $a .^{23}$ ), thus supporting alternative modes of activating caspases in human and worm cells. ${ }^{3}$ However, although the release of cytochrome $c$ from mitochondria is dispensable for CED-3 activation in $C$. elegans, these organelles are nonetheless implicated in cell death in the worm, as evidenced by the recent identification of CED-3 protease suppressor-6 (CPS-6) and worm AIF homolog-1 (WAH-1), homologs of the mammalian proapoptotic factors, endonuclease $G$ (EndoG) and apoptosis-inducing factor $(\mathrm{AIF})$, respectively, that are localized to mitochondria and
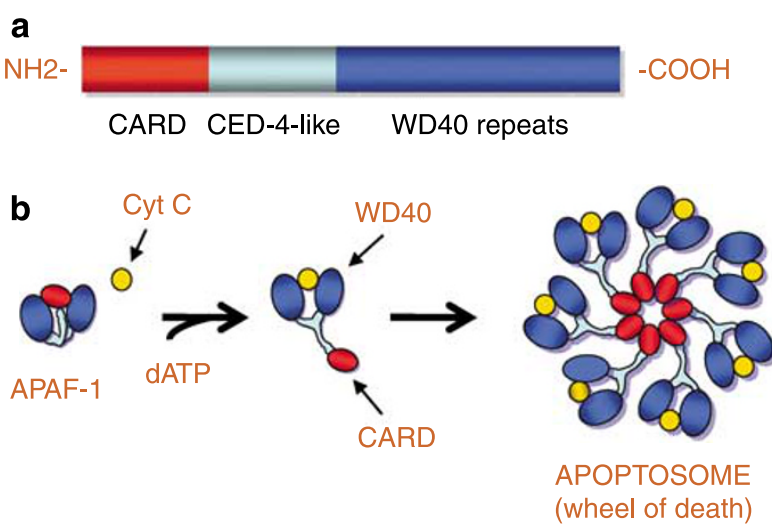

Figure 2 The wheel of death: formation of the apoptosome. (a) The Apaf-1 protein consists of three functional units: the CARD, which is responsible for recruiting caspase-9; a nucleotide-binding and oligomerization domain with sequence homology to CED-4, which is responsible for dATP/ATP-dependent oligomerization; and the C-terminal WD40 domain, which is responsible for binding of cytochrome $c$. (b) Sequential binding of cytochrome $c$ and dATP/ATP converts Apaf-1 from an autoinhibited monomeric state to a heptameric platform for caspase9 activation. The functional apoptosome adopts a wheel-like structure ${ }^{44}$ with the cytochrome $c$-binding domains protruding like spokes from the central hub of the wheel, which is comprised of the CED-4 and CARD regions released into the cytosol during apoptosis to promote DNA fragmentation. ${ }^{24}$

Homologs of many components of the mammalian apoptosis machinery have also been identified in the fruit fly, Drosophila melanogaster. Thus, the Drosophila Apaf-1 homolog, Drosophila Apaf-1-related killer (Dark) is critically important for the activation of caspases in the fruit fly. ${ }^{3}$ Dark contains a WD40 region, but RNA interference experiments failed to support a role for cytochrome $c$ in the apoptotic death of Drosophila cells. ${ }^{25}$ In fact, Dark was shown to form an octameric apoptosome in the presence of dATP, and cytochrome $c$ was not required for assembly of this complex, and when added, did not bind to the complex. ${ }^{26}$ On the other hand, Steller and co-workers ${ }^{27}$ have revealed that an apoptosis-like mechanism involving cytochrome $c-d$, one of two Drosophila cytochrome $c$ genes, is required for sperm differentiation in Drosophila. Moreover, these investigators reported in a recent study that cytochrome-c-d regulates developmental apoptosis of superfluous cells in the Drosophila retina, ${ }^{28}$ arguing for a role of cytochrome $c$ in caspase regulation of certain somatic cells in the fruit fly. The latter findings thus point to the possibility that the pathways of programmed cell death, while conserved through evolution, may be differently executed in different populations of cells, akin to the fugue of the Baroque era, with its multiple and intertwined statements of the same musical theme.

\section{Apaf-1 and Cytochrome $c$ Deficiency: Lessons from Mouse Models}

One year after the discovery of Apaf-1, two groups reported the generation of Apaf-1-deficient mice. ${ }^{29,30}$ The main finding was that virtually no apoptosis could be detected in the developing central nervous system (CNS) of these mice and, as a result, a huge number of neurons accumulated and formed protruding masses in the brain, with ensuing embryonic lethality. Interestingly, subsequent studies revealed that the forebrain outgrowth (fog) phenotype in mice can be attributed to low levels of Apaf- 1 expression due to aberrant processing of Apaf-1 mRNA. ${ }^{31}$ Hence, the Apaf-1-dependent pathway is of central importance for the controlled deletion of neurons during development. In addition, embryonic stem cells and fibroblasts derived from Apaf-1-deficient mice are resistant to intrinsic apoptosis stimuli such as $\gamma$-irradiation and etoposide, a chemotherapeutic agent, despite the normal release of cytochrome $c$ from mitochondria to the cytosol. ${ }^{29,30}$ Mice deficient for caspase- 9 or caspase-3 also display deformities of the fetal brain and the absence of normal apoptosis of neurons, ${ }^{32}$ thus testifying to the importance of apoptosome activation in neuronal developmental cell death. In contrast, postmitotic neurons were reported to be resistant to cytochrome $c$-dependent apoptosis due to a downregulation of Apaf- 1 during the process of differentiation. ${ }^{33}$ Cardiomyocytes and skeletal muscle cells are also refractory to apoptosome activation. ${ }^{34,35}$ The mechanism underlying this shift in apoptosome function in postmitotic cells remains unresolved; nevertheless, the downregulation of Apaf-1 could perhaps serve as a safeguard against inadvertent induction of apoptosis resulting from leakage of cytochrome $c$ from damaged mitochondria. 
Despite the remarkable resistance of Apaf-1-deficient thymocytes to various apoptotic stimuli, Apaf-1-dependent apoptosis has no apparent role in the negative selection of thymocytes expressing T-cell receptors reactive to selfantigens. ${ }^{36}$ Moreover, apart from the conspicuous CNS phenotype in Apaf-1-deficient mice, other organs develop normally, suggesting that other pathways of cell death can compensate for the loss of Apaf-1 in non-neural tissues during embryogenesis. For comparison, recent studies in the worm have suggested the existence of a cell-autonomous program of deletion of specific cell types during development that is independent of all the previously described cell death genes. ${ }^{37}$

Mice devoid of cytochrome $c$ die in utero by midgestation due to developmental defects. ${ }^{38}$ However, due to the obligate function of cytochrome $c$ in electron transport, its specific requirement for apoptosis is difficult to establish using such a model. To circumvent this problem, knock-in mice were engineered to express a mutant form of cytochrome $c$, capable of sustaining mitochondrial respiration but lacking Apaf-1-activating function. These mice were found to die perinatally with CNS defects similar to those seen in Apaf-1deficient animals. ${ }^{39}$ Interestingly, however, while cell death in Apaf-1-defective thymocytes is delayed in response to multiple proapoptotic stimuli, the cytochrome $c$-mutant cells died under some of these conditions, suggesting that perhaps Apaf-1 has some constitutive activity or might be regulated by factors other than cytochrome $c$. An alternative explanation is, of course, that the mutant form of cytochrome $c$ may retain residual binding to the WD40 region of Apaf-1, thus allowing it to activate apoptosis in some cells, under some circumstances. It should be noted in this context that apoptosome activation in neutrophils, key players in inflammation and host defense, was reported to display dramatically reduced requirements for cytochrome $c .^{40}$

One of the primary sites of action of $\mathrm{Bcl}-2$ is the prevention of cytochrome $c$ release from mitochondria, thereby blocking apoptosome activation. However, Bcl-2 also interferes with caspase activation induced by cytochrome $c$ microinjected directly into the cytoplasm, indicating that $\mathrm{Bcl}-2$ can, in fact, act downstream of mitochondria. ${ }^{41}$ Moreover, recent in vivo studies suggest that $\mathrm{Bcl}-2$ may have a broader role, at least in cells of the hematopoietic system, and could also regulate other putative scaffold proteins for caspase activation, independently of the cytochrome c/Apaf-1/procaspase- 9 pathway. ${ }^{42}$ Nevertheless, it remains possible that the mitochondria-dependent pathway of caspase activation is essential in some cell types, as evidenced by the CNS phenotype in mice defective for core components of the apoptosome. ${ }^{32}$ Bcl-2 also negatively regulates Beclin-1, a protein involved in autophagy ('self-eating'), ${ }^{43}$ which could have important implications for the role of $\mathrm{Bcl}-2$ in carcinogenesis; in other words, the oncogenic effects of $\mathrm{Bcl}-2$ may not be solely related to inhibition of apoptosis.

\section{The Wheel of Death: Apoptosomes as Platforms for Caspase Activation}

Classical biochemical reconstitution studies have demonstrated that Apaf-1 becomes competent to recruit procas- pase-9 in the presence of ATP/dATP upon binding to cytochrome $c .^{18}$ This recognition of procaspase- 9 by Apaf-1, primarily through CARD-CARD interactions, is essential for the formation of the apoptosome. Subsequent nucleotide exchange from dADP to dATP on Apaf-1 is proposed to cause a conformational change facilitating assembly of a protein complex in the shape of a wheel, known as the apoptosome. ${ }^{44}$ Structural studies revealed that the CARD and CED-4 homology domains form the hub of the wheel, while the seven spokes consist of WD40 domains, and procaspase-9 binds the hub (Figure 2). More recent studies of native apoptosomes isolated from the Jurkat T-cell line have suggested that the major constituents of the wheel of death, at least in these cells, are Apaf-1, procaspase-9, procaspase3 , X-linked inhibitor of apoptosis protein (XIAP), and cytochrome $c$, which was only bound transiently to the complex. ${ }^{45}$ $\mathrm{XIAP}$, a potent inhibitor of caspases, was suggested by these investigators to mediate the tethering of caspase- 3 to the apoptosome. In this scenario, the release from mitochondria of inhibitor of apoptosis protein (IAP) antagonists such as the second mitochondrial activator of caspases (Smac) may then serve to displace XIAP, leading to more efficient apoptosome activation.

The general scheme of caspase activation through the recruitment of procaspases to a specific adaptor protein complex is recapitulated in manifold ways in mammalian cells. Hence, activation of caspase-9, caspase-8/caspase-10, and caspase- 2 depends on the apoptosome, the death-inducing signaling complex (DISC), and the PIDDosome, respectively. ${ }^{22}$ The principal steps of DISC formation were briefly discussed in a previous section; however, a detailed understanding of this platform of death awaits further biochemical and structural characterization. Caspase-2, which shares the highest degree of sequence similarity of any mammalian caspase with the $C$. elegans cell death protease CED-3, is required for stress-induced apoptosis, ${ }^{8}$ but does not appear to play any role during development, according to the unremarkable phenotype of caspase-2-deficient mice. ${ }^{32}$ Recent studies suggest that caspase- 2 is activated in a complex consisting of RAIDD (receptor-interacting protein (RIP)-associated ICH-1/ CED-3-homologous protein with a death domain (DD)) and p53-induced protein with death domain (PIDD). ${ }^{46}$ The recent definition of the structure of the core components of the PIDDosome has revealed an asymmetric complex that comprises seven RAIDD DDs and five PIDD DDs. ${ }^{47}$ At present, it is unclear whether any additional cofactor(s) are involved in the assembly of this caspase-activating complex. Activation of the Drosophila caspase, Dronc also occurs in a multimeric protein complex, consisting of two wheel-shaped particles associated face-to-face, each involving eight molecules of Dark(ness). ${ }^{22}$

Recent studies have unveiled the composition of another caspase activation complex, termed the inflammasome. Generation of proinflammatory interleukin (IL)-1 $\beta$, via cleavage of its pro-form, requires the activity of caspase-1, and Tschopp and co-workers ${ }^{48}$ have shown that this occurs in a molecular complex containing caspase-1 and [NACHT, LRR and PYD (pyrin domain)-containing protein-1] (NALP1), a scaffold protein sharing structural homology with so-called nucleotide oligomerization domains (NODs), intracellular 
surveillance proteins that detect microbial signature molecules. Recent biochemical reconstitution studies further suggest that caspase-1 activation in the NALP1 inflammasome does not require but is enhanced by the adaptor protein apoptosis-associated speck-like CARD protein (ASC), which contains PYD and CARD domains. ${ }^{49}$ However, the precise stoichiometric relations of the various components of the NALP1 inflammasome await its structural characterization.

\section{Spinning the Roulette Wheel: Direct and Indirect Modulation of the Apoptosome}

Numerous mechanisms of apoptosome modulation in normal and disease states have been described. Regulation of the release of cytochrome $c$ from mitochondria, the most important upstream signal for Apaf-1 activation, has been extensively reviewed elsewhere. ${ }^{50}$ Procaspase- 9 , which is activated upon assembly of the wheel of death, is subject to direct regulation through phosphorylation, ${ }^{51}$ and active caspase- 9 , in turn, is a target of inhibition by XIAP as well as certain virus-encoded proteins. ${ }^{52}$ Apaf- 1 itself is also subject to modulation both at the transcriptional and posttranslational level. Thus, different splice variants of Apaf-1 have been identified, ${ }^{53,54}$ although the physiological significance of these various isoforms remains to be firmly established. Silencing of Apaf-1 expression through hypermethylation of the Apaf-1 gene promoter is observed in certain types of human cancer, and is discussed in more detail below. Apaf- 1 is also subject to proteolytic processing by caspases, an event that was postulated to initiate the release of caspases from the apoptosome during apoptosis; ${ }^{55}$ alternatively, the degradation of Apaf-1 might serve as a negative feedback mechanism that dampens the apoptotic response. Moreover, redistribution of Apaf-1 from the cytosol to other subcellular compartments, including the nucleus, has been documented, ${ }^{56}$ and constitutive mislocalization of Apaf- 1 to the plasma membrane was reported in certain apoptosisresistant cancer cells. ${ }^{57}$ The modulation of intrinsic (mitochondria-dependent) apoptosis, and the potential for therapeutic utilization of these pathways in cancer patients, will be discussed in the following sections.

Apoptosome formation can be reconstituted in vitro with the addition of cytochrome $c$ and dATP/ATP to cell lysates. ${ }^{58}$ More recent investigations show that cytochrome $c$ binding to Apaf-1 induces hydrolysis of dATP to dADP, which is subsequently replaced by exogenous dATP, and dATP hydrolysis and exchange on Apaf-1 are two required steps for apoptosome formation. ${ }^{59}$ However, physiological levels of nucleotides inhibit the cytochrome $c$-initiated apoptosome formation and caspase- 9 activation through a mechanism of direct binding to cytochrome $c{ }^{60}$ These data thus suggest that intracellular nucleotide pools are pro-survival factors that act as a barrier to apoptosis induction. Furthermore, normal intracellular concentrations of potassium $\left(\mathrm{K}^{+}\right)$may suppress apoptosome function, and this inhibitory effect of $\mathrm{K}^{+}$is apparently antagonized in a concentration-dependent manner by cytochrome $c{ }^{61}$ The latter findings are in accord with the view that a rapid and extensive release of cytochrome $c$ is required for propagation of the apoptotic signal. ${ }^{62}$
Recent studies using cell-free systems have demonstrated that physiological levels of calcium ions can negatively affect the oligomerization of the apoptosome by inhibiting nucleotide exchange of Apaf-1; calcium was found to prevent Apaf-1mediated activation of caspase- 9 , but did not have any significant effects on the assembled apoptosome. ${ }^{63}$ However, it remains to be determined whether a similar mechanism operates in intact cells, and how these novel findings are to be reconciled with the well-known role of calcium as a trigger of either necrosis or apoptosis in mammalian cells as well as in nematodes. ${ }^{64}$

Numerous proteins can affect the activity of the apoptosome (for an extensive list of apoptosome-modulating proteins, see reference Schafer and Kornbluth ${ }^{65}$ ). Heat-shock proteins (Hsps) are molecular chaperones that are induced in response to a variety of cellular stresses and function to protect the cell (Figure 3 ). Hsp70 binds to Apaf- 1 and prevents the recruitment of procaspase- 9 to the apoptosome. 66,67 Interestingly, studies using Apaf-1-deficient cells demonstrated that Hsp70 can also interfere with caspase-independent pathways of apoptosis, through the suppression of AIF-induced chromatin condensation. ${ }^{68}$ Hsp90 inhibits cytochrome $c$-mediated oligomerization of Apaf- 1 and thereby

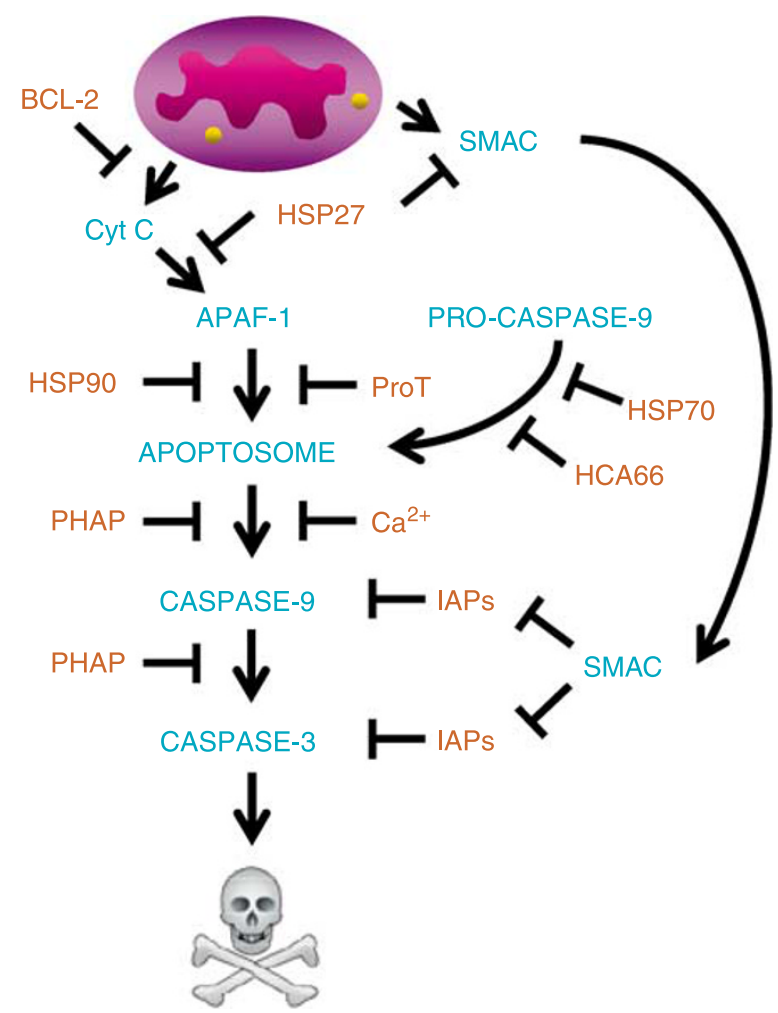

Figure 3 Physiological apoptosome regulation. Formation of the apoptosome is initiated upon release from the mitochondrial inner membrane space of cytochrome $c$, the cofactor for Apaf-1. Studies in recent years have revealed numerous other cellular factors that regulate Apaf-1 oligomerization, procaspase-9 recruitment, and apoptosome activation. Some of the key regulators, including the oncoprotein ProT and the tumor suppressor protein PHAP, and their principal points of interaction with the major steps of apoptosome formation and activation, are depicted in this schematic figure. See the text for a discussion of the positive and negative modulation of apoptosome function by these factors 
activation of procaspase-9 (reference Pandey et al. ${ }^{69}$ ). Hsp27 inhibits cytochrome $c$-mediated caspase activation through a mechanism that involves binding to and sequestering of cytochrome $c$, preventing its interaction with Apaf-1 (references Bruey et al. ${ }^{70}$ and Pandey et al. ${ }^{71}$ ). Moreover, Hsp27 has been found to prevent Smac release from mitochondria in multiple myeloma cell lines and patient-derived cells, which could help to explain the resistance of these cancer cells to certain apoptotic stimuli. ${ }^{72}$

Putative HLA-DR-associated protein-1 (PHAP1) and prothymosin- $\alpha$ (ProT) were identified as apoptosome regulators in a screen for small molecules that activate caspase-3 (reference Jiang et al. ${ }^{73}$ ). PHAP1 appears to facilitate caspase- 9 activation after apoptosome formation, whereas ProT negatively regulates caspase- 9 activation by inhibiting assembly of the apoptosome. ProT is an oncoprotein required for cell proliferation, and these data thus indicate that one of its biochemical functions is to prevent apoptosome formation. Indeed, such properties are consistent with the observation that other negative regulators of apoptosis such as $\mathrm{Bcl}-2$ also possess oncogenic activities. ProT acts both in the cytoplasm and in the nucleus, and recent studies show that overexpression of ProT may also elicit a p53 response. ${ }^{74}$ PHAPs, on the other hand, function as tumor suppressors and may perhaps inhibit cell growth by promoting intrinsic apoptosis signaling. Indeed, a recent in vitro study showed that breast cancer cells are unusually sensitive to cytochrome $c$-induced caspase activation due to the overexpression of PHAP1, thus raising the possibility that this mechanism might be exploited for therapeutic purposes. ${ }^{75}$ Recent investigations suggest that PHAP1 may enhance the catalytic activity of caspase-3 in the apoptosome complex. ${ }^{45}$ However, further studies are warranted to elucidate the precise mechanism of action of these apoptosome-modulating factors, and their role in human cancer.

\section{Apoptosome Dysfunction in Human Cancer: Mechanisms of Apaf-1 Inactivation}

Mutations in the p53 tumor suppressor gene, or inactivation of p53-dependent signaling, are common in human cancer and may account for resistance to apoptosis in a large proportion of cancer patients. ${ }^{76}$ Apaf- 1 is a p53 target gene, ${ }^{77}$ and in vivo studies have implied a role for the apoptosome in controlling cancer development insofar as inactivation of Apaf-1 or caspase- 9 substituted for $p 53$ loss in promoting the oncogenic transformation of myc-expressing cells. ${ }^{78}$ Apaf- 1 is also a direct target for E2F (reference Moroni et al. ${ }^{79}$ ), another transcription factor that is capable of promoting both cell cycle progression and apoptosis, and Apaf-1 deficiency may impair the response to E2F-induced apoptosis. ${ }^{80}$ However, a recent report has questioned whether Apaf-1 and caspase- 9 function as tumor suppressors and suggests that Apaf- 1 is not a critical determinant of the responsiveness of mycinduced lymphomas to chemotherapeutic drugs. ${ }^{81}$ Notwithstanding these discrepancies, which may be related, at least in part, to methodological differences, the importance of apoptosome-dependent apoptosis is supported by the observation that Apaf- 1 is frequently silenced or inactivated in human cancer.
The first report of Apaf-1 inactivation in human cancer was the demonstration that metastatic malignant melanomas, which are notoriously resistant to all forms of anticancer treatment, often loose expression of the Apaf- 1 protein. ${ }^{82}$ Epigenetic gene silencing was found to be the likely cause of Apaf-1 downregulation, although the exact mechanism by which methylation switches off the Apaf-1 gene was not clarified. Nevertheless, the Apaf-1 gene could be turned back on by treating cultured melanoma cells with inhibitors of DNA methylation or histone deacetylation, and this treatment rescued the apoptotic defect and markedly enhanced the chemoresponsiveness of melanoma cells. ${ }^{82}$ Subsequent studies performed in other laboratories have provided further support for this mechanism of Apaf-1 inactivation in metastatic melanomas, ${ }^{83}$ although it should be noted that loss of Apaf-1 may not be the sole determinant of chemoresistance in this type of cancer. ${ }^{84}$ Nevertheless, the fact that a substantial proportion of leukemia-derived cell lines and primary leukemic cells, ${ }^{85}$ as well as cells from glioblastomas ${ }^{86}$ and cervical carcinomas ${ }^{87}$ may also inactivate Apaf-1 through a similar mechanism, further suggests that apoptosome deregulation may represent a significant event in human cancer. Indeed, loss of Apaf-1 expression is associated with tumor progression and adverse prognosis in colorectal cancer, ${ }^{88}$ and silencing of Apaf-1 in B-cell chronic lymphocytic leukemia (B-CLL) correlates with poor prognosis in cases with concomitant p53 mutations. ${ }^{89}$ Moreover, a recent and comprehensive study of human leukemia samples provided evidence that overexpression of Dnmt1, a mammalian maintenance DNA methyltransferase, underlies hypermethylation of the Apaf-1 gene. ${ }^{90}$ Dnmt1 may thus serve as a novel therapeutic target in cancer cells exhibiting loss of Apaf-1 expression due to gene silencing.

Defective cytochrome $c$-dependent caspase activation has also been documented in ovarian cancer cell lines, despite abundant Apaf-1 expression; ${ }^{91}$ the mechanism underlying the diminished apoptosome function in these cells was not clarified, but could be related to a defective recruitment of procaspase- 9 to the apoptosome. ${ }^{92}$ Moreover, recent studies show that non-small-cell lung carcinoma cells are resistant to cytochrome $c$-dependent apoptosome activation despite an upregulation of Apaf-1 expression, suggesting that these cancer cells may express an unidentified factor that suppresses apoptosome function. ${ }^{93}$ Of interest, recent studies have unearthed a novel Apaf-1-regulating protein termed hepatocellular carcinoma antigen 66 (HCA66) (reference Piddubnyak et al. ${ }^{94}$ ). This protein binds to the CED-4 domain of Apaf-1 and appears to promote Apaf-1-dependent apoptosis by potentiating caspase- 9 recruitment to the apoptosome. HCA66 expression was found to be decreased in cell lines derived from patients with neurofibromatosis type 1, a neurocutaneous disorder that carries a high risk of tumor formation, and it was suggested that insufficient expression of HCA66 could account for the observed apoptosis defect in these cell lines. ${ }^{94}$

Cell lines derived from Burkitt lymphomas are frequently refractory to apoptosis induction by anticancer agents, and we recently provided a putative explanation for this chemoresistance. ${ }^{57}$ Hence, we found that cytochrome $c$ failed 
to stimulate apoptosome formation and caspase activation in cytosolic extracts of Burkitt-derived cell lines, due to insufficient levels of Apaf-1 in the cytosol (the total cellular amount of Apaf-1 protein, however, was not diminished, thus ruling out gene silencing). Enforced expression of exogenous Apaf- 1 increased its concentration in the cytosolic compartment, restored cytochrome $c$-dependent caspase activation, and rendered the p53-deficient Raji cell line sensitive to etoposide-induced apoptosis. ${ }^{57}$ Moreover, disruption of lipid raft domains in chemoresistant B-cell lines liberated endogenous Apaf- 1 from its ectopic plasma membrane localization and restored sensitivity to cytochrome $c$-dependent apoptosis. These findings suggest that lipid raft sequestration of Apaf-1 may constitute a novel mechanism of chemoresistance in B lymphoma. The mechanism underlying this sequestration remains unknown, but could involve post-translational modifications of Apaf-1, thus targeting this protein to lipid raft domains. These studies further underscore the fundamental importance of correct compartmentalization of the cell death machinery, ${ }^{95}$ and suggest that targeting of lipid rafts could serve to promote sensitivity of B lymphomas to conventional anticancer treatment.

Upregulation of various members of the IAP family of endogenous caspase inhibitors is common in human cancer, and these proteins could thus serve as important mediators of malignant potential and chemoresistance. ${ }^{96}$ Indeed, survivin was reported 10 years ago to be undetectable in terminally differentiated adult tissues, but prominently expressed in all of the most common human cancers of lung, colon, pancreas, prostate and breast. ${ }^{97}$ Survivin and other IAPs are therefore attractive therapeutic targets, and efforts are under way to develop IAP inhibitors that may be useful for the treatment of human cancer. ${ }^{96}$ Smac alleviates caspase inhibition by IAPs, and synthetic Smac-derived peptides have been shown in preclinical studies to sensitize cancer cells both to death receptor-mediated (extrinsic) apoptosis stimulation and chemotherapeutic drugs. For instance, eradication of established tumors upon combined treatment with Smac peptides and recombinant TRAIL was demonstrated in a mouse model of malignant glioma. ${ }^{98}$ Similarly, Smac peptides in combination with chemotherapeutic agents were found to induce tumor regression in mice bearing nonsmall cell lung carcinomas. ${ }^{99}$ Of note, our recent in vitro studies have shown that Smac-mediated potentiation of staurosporine- or lactacystin (proteasome inhibition)-induced apoptosis in B lymphoma cell lines is critically dependent upon the formation of a functional apoptosome. ${ }^{100}$ The latter findings thus suggest that an assessment of the expression of core components of the apoptosome should be considered if and when Smac-based anticancer therapies enter into the clinical setting.

Table 1 Some examples of therapeutic modulation of apoptosome function

\begin{tabular}{|c|c|c|}
\hline Molecular target & Active agent/principle & Reference \\
\hline \multicolumn{3}{|l|}{ 1. Pre-apoptosome } \\
\hline \multirow[t]{2}{*}{ Bcl-2-like proteins } & Bcl-2 antisense (downregulates Bcl-2 expression) & Webb et al. ${ }^{102}$ \\
\hline & $\begin{array}{l}\text { Bcl-X antisense (splice-specific antisense; redirects mRNA processing from antiapoptotic } B c l-X_{L} \\
\text { to proapoptotic } B c l-X_{S} \text { ) }\end{array}$ & Taylor et al. ${ }^{103}$ \\
\hline \multirow[t]{2}{*}{ BH3-only proteins } & SAHBs (BH3 peptide mimetics; induce Bax/Bak activation) & Walensky et al. ${ }^{104}$ \\
\hline & ABT-737 (small-molecule BH3 mimetic; inhibits Bcl-2/Bcl- $\mathrm{X}_{\mathrm{L}}$ ) & Oltersdorf et al. $^{105}$ \\
\hline \multicolumn{3}{|l|}{ 2. Apoptosome } \\
\hline Cytochrome c & Triacsin C (ACS inhibitor; induces mitochondrial release of cytochrome $c$ ) & Mashima et al. ${ }^{106}$ \\
\hline \multirow{4}{*}{ Apaf-1 } & 5-AZA (prevents methylation of the Apaf-1 gene promoter, inducing Apaf- 1 gene transcription) & Soengas et al. ${ }^{82}$ \\
\hline & Compound 2 (promotes Apaf-1 oligomerization) & Nguyen and Wells ${ }^{10}$ \\
\hline & MCD (cholesterol-depleting aqent: prevents ectopic lipid raft sequestration of Apaf-1) & Sun etal ${ }^{57}$ \\
\hline & LAQ824 (HDAC inhibitor; induces transcription of the Apaf-1 gene) & Wang et al. ${ }^{108}$ \\
\hline Caspase-9 & LAQ824 (HDAC inhibitor; induces transcription of the CASP9 gene) & Wang et al. ${ }^{108}$ \\
\hline \multicolumn{3}{|l|}{ 3. Post-apoptosome } \\
\hline \multirow[t]{4}{*}{ IAPs } & XIAP antisense (downregulates XIAP expression) & Hu et al. ${ }^{109}$ \\
\hline & XAntags (small-molecule XIAP antagonists) & Schimmer et al. ${ }^{110}$ \\
\hline & Survivin-mutant adenovirus (dominant-negative survivin) & Mesri et al. ${ }^{111}$ \\
\hline & Shepherdin (peptide mimetic; destabilizes HSP90/survivin binding) & Plescia et al. ${ }^{112}$ \\
\hline \multirow[t]{2}{*}{ Smac } & Cell-permeable Smac peptide (inhibits XIAP function) & Fulda et al. ${ }^{98}$ \\
\hline & Small molecule Smac mimetic (inhibits XIAP function) & Li et al. ${ }^{113}$ \\
\hline XAF1 & IFN- $\beta$ (reactivates expression of XAF1, an IAP antagonist) & Leaman et al. $^{114}$ \\
\hline
\end{tabular}

Abbreviations: ACS, acyl-CoA synthetase; Apaf-1, apoptotic protease-activating factor-1; 5-AZA, 5-aza-2'-deoxycytidine; BH3, Bcl-2 homology domain 3; HDAC, histone deacetylase; HSP, heat-shock protein; IAP, inhibitor of apoptosis protein; IFN, interferon; MCD, methyl- $\beta$-cyclodextrin; PETCM, $\alpha$-(trichloromethyl)-4pyridineethanol; SAHB, stabilized $\alpha$-helix of Bcl-2 domains; Smac, second mitochondrial activator of caspases; XA, XIAP antagonist; XAF1, XIAP-associated factor1: XIAP, X-linked IAP. This list provides a selection of key references describing some promising avenues for apoptosome-targeted treatment of human disease, including cancer/chemoresistance. For a comprehensive and recent overview of apoptosis-based therapies, including agents that target both the extrinsic and intrinsic pathways of apoptosis signaling, along with information on pharmaceutical companies that are currently developing such therapies, see Fadeel and Orrenius, ${ }^{2}$ Reed, ${ }^{101}$ and Fischer and Schulze-Osthoff. ${ }^{115}$ 


\section{Conclusions}

Significant progress has been made in recent years in understanding the role of intrinsic, apoptosome-dependent apoptosis during embryogenesis and for maintenance of tissue homeostasis. Moreover, there is mounting evidence, discussed herein, supporting a role for apoptosome defects in human cancer, with important implications for carcinogenesis as well as chemoresistance. Cancer treatment is now moving toward targeting the specific molecular aberrations in cancer cells, ${ }^{101}$ and the challenge that lies ahead is thus to provide custom-tailored treatments to match the specific apoptosis lesions in cancer cells. Some examples of potential therapeutic interventions based on direct or indirect modulation of apoptosome function are provided in Table 1, along with key references. In conclusion, restoration of apoptosis sensitivity in human cancer through the therapeutic targeting of apoptosomes, molecular engines for caspase activation, or other components of the intrinsic pathway of apoptosis, may ultimately yield improved clinical outcomes in cancer patients.

Acknowledgements. BF is supported by research grants from the Swedish Research Council, Swedish Cancer Foundation, Swedish Children's Cancer Foundation, and the Human Frontier Science Program, and SP is supported by the National Medical Research Council, Biomedical Research Council, and the Academic Research Fund (National University of Singapore, Singapore).

1. Jacobson MD, Weil M, Raff MC. Programmed cell death in animal development. Cell 1997; 88: 347-354.

2. Fadeel B, Orrenius S. Apoptosis: a basic biological phenomenon with wide-ranging implications in human disease. J Intern Med 2005; 258: 479-517.

3. Danial NN, Korsmeyer SJ. Cell death: critical control points. Cell 2004; 116: 205-219.

4. Siegel RM, Chan FK, Chun HJ, Lenardo MJ. The multifaceted role of Fas signaling in immune cell homeostasis and autoimmunity. Nat Immunol 2000; 1: 469-474.

5. Adams JM, Cory S. Apoptosomes: engines for caspase activation. Curr Opin Cell Biol 2002; 14: 715-720.

6. Luo X, Budihardjo I, Zou H, Slaughter C, Wang X. Bid, a Bcl-2-interacting protein, mediates cytochrome $c$ release from mitochondria in response to activation of cell surface death receptors. Cell 1998; 94: 481-490.

7. Li H, Zhu H, Xu CJ, Yuan J. Cleavage of Bid by caspase 8 mediates the mitochondrial damage in the Fas pathway of apoptosis. Cell 1998; 94: 491-501.

8. Lassus P, Opitz-Araya X, Lazebnik Y. Requirement for caspase-2 in stress-induced apoptosis before mitochondrial permeabilization. Science 2002; 297: 1352-1354.

9. Hanahan D, Weinberg RA. The hallmarks of cancer. Cell 2000; 100: 57-70.

10. Kaufmann SH, Vaux DL. Alterations in the apoptotic machinery and their potential role in anticancer drug resistance. Oncogene 2003; 22: 7414-7430.

11. Lettre G, Hengartner MO. Developmental apoptosis in C. elegans: a complex CEDnario. Nat Rev Mol Cell Biol 2006; 7: 97-108.

12. Yuan J, Shaham S, Ledoux S, Ellis HM, Horvitz HR. The $C$. elegans cell death gene ced-3 encodes a protein similar to mammalian interleukin-1 $\beta$-converting enzyme. Cell 1993; 75: 641-652.

13. Hengartner MO, Horvitz HR. C. elegans cell survival gene ced-9 encodes a functional homolog of the mammalian proto-oncogene Bcl-2. Cell 1994; 76: 665-676.

14. Vaux DL, Cory S, Adams JM. Bcl-2 gene promotes haemopoietic cell survival and cooperates with c-myc to immortalize pre-B cells. Nature 1998; 335: 440-442.

15. Hockenbery D, Nunez G, Milliman C, Schreiber RD, Korsmeyer SJ. Bcl-2 is an inner mitochondrial membrane protein that blocks programmed cell death. Nature 1990; 348 : 334-336.

16. Vaux DL, Weissman IL, Kim SK. Prevention of programmed cell death in Caenorhabditis elegans by human Bcl-2. Science 1992; 258: 1955-1957.

17. Zou H, Henzel WJ, Liu X, Lutschg A, Wang X. Apaf-1, a human protein homologous to C. elegans CED-4, participates in cytochrome $c$-dependent activation of caspase-3. Cell 1997; 90: 405-413.

18. Li P, Nijhawan D, Budihardjo I, Srinivasula SM, Ahmad M, Alnemri ES et al. Cytochrome $c$ and DATP-dependent formation of Apaf-1/caspase-9 complex initiates an apoptotic protease cascade. Cell 1997; 91: 479-489.

19. Yang J, Liu X, Bhalla K, Kim CN, Ibrado AM, Cai J et al. Prevention of apoptosis by Bcl-2 release of cytochrome $c$ from mitochondria blocked. Science 1997; 275: 1129-1132.
20. Kluck RM, Bossy-Wetzel E, Green DR, Newmeyer DD. The release of cytochrome c from mitochondria: a primary site for Bcl-2 regulation of apoptosis. Science 1997; 275 1132-1136.

21. Shaham $S$, Horvitz HR. An alternatively spliced $C$. elegans ced-4 RNA encodes a novel cell death inhibitor. Cell 1996; 86: 201-208.

22. Bao Q, Shi Y. Apoptosome: a platform for the activation of initiator caspases. Cell Death Differ 2007; 14: 56-65.

23. Hausmann G, O'Reilly LA, Driel R, Beaumont JG, Strasser A, Adams JM et al. Proapoptotic apoptosis protease-activating factor 1 (Apaf-1) has a cytoplasmic localization distinct from Bcl-2 or Bcl-X $X_{L}$ J Cell Biol 2000; 149: 623-634.

24. Wang $X$, Yang C, Chai J, Shi Y, Xue D. Mechanisms of AlF-mediated apoptotic DNA degradation in Caenorhabditis elegans. Science 2002; 298: 1587-1592.

25. Zimmermann KC, Ricci JE, Droin NM, Green DR. The role of ARK in stress-induced apoptosis in Drosophila cells. J Cell Biol 2002; 156: 1077-1087.

26. Yu X, Wang L, Acehan D, Wang X, Akey CW. Three-dimensional structure of a double apoptosome formed by the Drosophila Apaf-1 related killer. J Mol Biol 2006; 355 577-589.

27. Arama E, Agapite J, Steller H. Caspase activity and a specific cytochrome $c$ are required for sperm differentiation in Drosophila. Dev Cell 2003; 4: 687-697.

28. Mendes CS, Arama E, Brown S, Scherr H, Srivastava M, Bergmann A et al. Cytochrome $c-d$ regulates developmental apoptosis in the Drosophila retina. EMBO Rep 2006; 7 933-939.

29. Cecconi F, Alvarez-Bolado G, Meyer BI, Roth KA, Gruss P. Apaf-1 (CED-4 homolog) regulates programmed cell death in mammalian development. Cell 1998; 94: 727-737.

30. Yoshida H, Kong YY, Yoshida R, Elia AJ, Hakem A, Hakem R et al. Apaf-1 is required for mitochondrial pathways of apoptosis and brain development. Cell 1998; 94: 739-750.

31. Honarpour N, Gilbert SL, Lahn BT, Wang X, Herz J. Apaf-1 deficiency and neural tube closure defects are found in fog mice. Proc Natl Acad Sci USA 2001; 98: 9683-9687.

32. Ranger AM, Malynn BA, Korsmeyer SJ. Mouse models of cell death. Nat Genet 2001; 28 113-118.

33. Wright KM, Linhoff MW, Potts PR, Deshmukh M. Decreased apoptosome activity with neuronal differentiation sets the threshold for strict IAP regulation of apoptosis. J Cell Bio 2004; 167: 303-313.

34. Burgess DH, Svensson M, Dandrea T, Grönlund K, Hammarquist F, Orrenius $S$ et al. Human skeletal muscle cytosols are refractory to cytochrome $c$-dependent activation of type II caspases and lack Apaf-1. Cell Death Differ 1999; 6: 256-261.

35. Potts MB, Vaughn AE, McDonough H, Patterson C, Deshmukh M. Reduced Apaf-1 levels in cardiomyocytes engage strict regulation of apoptosis by endogenous XIAP. J Cell Biol 2005; 171: 925-930.

36. Hara H, Takeda A, Takeuchi M, Wakeham AC, Itie A, Sasaki M et al. The apoptotic protease-activating factor 1-mediated pathway of apoptosis is dispensable for negative selection of thymocytes. J Immunol 2002; 168: 2288-2295.

37. Abraham MC, Lu Y, Shaham S. A morphologically conserved non-apoptotic program promotes linker cell death in Caenorhabditis elegans. Dev Cell 2007; 12: 73-86.

38. Li K, Li Y, Shelton JM, Richardson JA, Spencer E, Chen ZJ et al. Cytochrome $c$ deficiency causes embryonic lethality and attenuates stress-induced apoptosis. Cell 2000; 101 389-399.

39. Hao Z, Duncan GS, Chang CC, Elia A, Fang M, Wakeham A et al. Specific ablation of the apoptotic functions of cytochrome $c$ reveals a differential requirement for cytochrome $c$ and Apaf-1 in apoptosis. Cell 2005; 121: 579-591.

40. Murphy BM, O'Neill AJ, Adrain C, Watson RW, Martin SJ. The apoptosome pathway to caspase activation in primary human neutrophils exhibits dramatically reduced requirements for cytochrome c. J Exp Med 2003; 197: 625-632.

41. Zhivotovsky B, Orrenius S, Brustugun OT, Døskeland SO. Injected cytochrome $c$ induces apoptosis. Nature 1998; 391: 449-450.

42. Marsden VS, O'Connor L, O'Reilly LA, Silke J, Metcalf D, Ekert PG et al. Apoptosis initiated by Bcl-2-regulated caspase activation independently of the cytochrome $c / A p a f-1 /$ caspase-9 apoptosome. Nature 2002; 419: 634-637.

43. Pattingre S, Tassa A, Qu X, Garuti R, Liang XH, Mizushima N et al. Bcl-2 antiapoptotic proteins inhibit Beclin 1-dependent autophagy. Cell 2005; 122: 927-939.

44. Acehan D, Jiang X, Morgan DG, Heuser JE, Wang X, Akey CW. Three-dimensional structure of the apoptosome: implications for assembly, procaspase- 9 binding, and activation. Mol Cell 2002; 9: 423-432.

45. Hill MM, Adrain C, Duriez PJ, Creagh EM, Martin SJ. Analysis of the composition, assembly kinetics and activity of native Apaf-1 apoptosomes. EMBO J 2004; 23 2134-2145.

46. Tinel A, Tschopp J. The PIDDosome, a protein complex implicated in activation of caspase-2 in response to genotoxic stress. Science 2004; 304: 843-846.

47. Park HH, Logette E, Raunser S, Cuenin S, Walz T, Tschopp J et al. Death domain assembly mechanism revealed by crystal structure of the oligomeric PIDDosome core complex. Cell 2007; 128: 533-546.

48. Martinon F, Burns K, Tschopp J. The inflammasome: a molecular platform triggering activation of inflammatory caspases and processing of pro-IL- $\beta$. Mol Cell 2002; 10 : 417-426.

49. Faustin B, Lartigue L, Bruey JM, Luciano F, Sergienko E, Bailly-Maitre B et al. Reconstituted NALP1 inflammasome reveals two-step mechanism of caspase-1 activation. Mol Cell 2007; 225: 713-724. 
50. Garrido C, Galluzzi L, Brunet M, Puig PE, Didelot C, Kroemer G. Mechanisms of cytochrome $c$ release from mitochondria. Cell Death Differ 2006; 13: 1423-1433.

51. Cardone MH, Roy N, Stennicke HR, Salvesen GS, Franke TF, Stanbridge E et al. Regulation of cell death protease caspase-9 by phosphorylation. Science 1998; 282: 1318-1321.

52. Eckelman BP, Salvesen GS, Scott FL. Human inhibitor of apoptosis proteins: why XIAP is the black sheep of the family. EMBO Rep 2006; 7: 988-994.

53. Benedict MA, Hu Y, Inohara N, Nunez G. Expression and functional analysis of Apaf-1 isoforms. Extra WD40 repeat is required for cytochrome $c$ binding and regulated activation of procaspase-9. J Biol Chem 2000; 275: 8461-8468.

54. Ogawa T, Shiga K, Hashimoto S, Kobayashi T, Horii A, Furukawa T. APAF-1-ALT, a novel alternative splicing form of APAF-1, potentially causes impeded ability of undergoing DNA damage-induced apoptosis in the LNCaP human prostate cancer cell line. Biochem Biophys Res Commun 2003; 306: 537-543.

55. Lauber K, Appel HA, Schlosser SF, Gregor M, Schulze-Osthoff K, Wesselborg S. The adapter protein apoptotic protease-activating factor-1 (Apaf-1) is proteolytically processed during apoptosis. J Biol Chem 2001; 276: 29772-29781.

56. Besse B, Cande C, Spano JP, Martin A, Khayat D, Le Chevalier T et al. Nuclear localization of apoptosis protease activating factor-1 predicts survival afte tumor resection in early-stage non-small cell lung cancer. Clin Cancer Res 2004; 10 : $5665-5669$.

57. Sun Y, Orrenius S, Pervaiz S, Fadeel B. Plasma membrane sequestration of apoptotic protease-activating factor-1 in human B lymphoma cells: a novel mechanism of chemoresistance. Blood 2005; 105: 4070-4077.

58. Liu X, Kim CN, Yang J, Jemmerson R, Wang X. Induction of apoptotic program in cell-free extracts: requirement for dATP and cytochrome c. Cell 1996; 86: 147-157.

59. Kim H, Du F, Fang M, Wang X. Formation of apoptosome is initiated by cytochrome $c$-induced dATP hydrolysis and subsequent nucleotide exchange on Apaf-1. Proc Natl Acad Sci USA 2005; 102: 17545-17550.

60. Chandra D, Bratton SB, Person MD, Tian Y, Martin AG, Ayres M et al. Intracellula nucleotides act as critical prosurvival factors by binding to cytochrome $c$ and inhibiting apoptosome. Cell 2006; 125: 1333-1346.

61. Cain K, Langlais C, Sun X-M, Brown D, Cohen G. Physiological levels of $K^{+}$ inhibit cytochrome $c$-dependent formation of the apoptosome. J Biol Chem 2001; 276 41985-41990.

62. Munoz-Pinedo C, Guio-Carrion A, Goldstein JC, Fitzgerald P, Newmeyer DD, Green DR. Different mitochondrial intermembrane space proteins are released during apoptosis in a manner that is coordinately initiated but can vary in duration. Proc Natl Acad Sci USA 2006; 103: 11573-11578.

63. Bao Q, Lu W, Rabinowitz J, Shi Y. Calcium blocks formation of apoptosome by preventing nucleotide exchange in Apaf-1. Mol Cell 2007; 25: 181-192.

64. Orrenius S, Zhivotovsky B, Nicotera P. Regulation of cell death: the calcium-apoptosis link. Nat Rev Mol Cell Biol 2003; 4: 552-565.

65. Schafer ZT, Kornbluth S. The apoptosome: physiological, developmental, and pathological modes of regulation. Dev Cell 2006; 10: 549-561.

66. Beere H, Wolf B, Cain K, Mosser D, Mahboubi A, Kuwana T et al. Heat shock protein 70 inhibits apoptosis by preventing recruitment of procaspase-9 to the Apaf-1 apoptosome. Nat Cell Biol 2000; 2: 469-475.

67. Saleh A, Srinivasula SM, Balkir L, Robbins PD, Alnemri ES. Negative regulation of the Apaf-1 apoptosome by Hsp70. Nat Cell Biol 2000; 2: 476-483.

68. Ravagnan L, Gurbuxani S, Susin SA, Maisse C, Daugas E, Zamzami N et al. Heat shock protein 70 antagonizes apoptosis-inducing factor. Nat Cell Biol 2001; 3: 839-843.

69. Pandey P, Saleh A, Nakazawa A, Kumar S, Srinivasula SM, Kumar V et al. Negative regulation of cytochrome $c$-mediated oligomerization of Apaf-1 and activation of procaspase- 9 by heat shock protein 90 . EMBO J 2000; 19: 4310-4322.

70. Bruey JM, Ducasse C, Bonniaud P, Ravagnan L, Susin S, Diaz-Latoud C et al. Hsp 27 negatively regulates cell death by interacting with cytochrome c. Nat Cell Biol 2000; 2 . 645-652.

71. Pandey P, Farber R, Nakazawa A, Kumar S, Bharti A, Nalin C et al. Hsp27 functions as a negative regulator of cytochrome $c$-dependent activation of procaspase-3. Oncogene 2000; 19: 1975-1981.

72. Chauhan D, Li G, Hideshima T, Podar K, Mitsiades C, Mitsiades N et al. Hsp27 inhibits release of mitochondrial protein Smac in multiple myeloma cells and confers dexamethasone resistance. Blood 2003; 102: 3379-3386.

73. Jiang X, Kim HE, Shu H, Zhao Y, Zhang H, Kofron J et al. Distinctive roles of PHAP proteins and prothymosin- $\alpha$ in a death regulatory pathway. Science 2003; 299: 223-226.

74. Kobayashi T, Wang T, Maezawa M, Kobayashi M, Ohnishi S, Hatanaka K et al. Overexpression of the oncoprotein prothymosin- $\alpha$ triggers a p53 response that involves p53 acetylation. Cancer Res 2006; 66: 3137-3144.

75. Schafer ZT, Parrish AB, Wright KM, Margolis SS, Marks JR, Deshmukh M et al. Enhanced sensitivity to cytochrome $c$-induced apoptosis mediated by PHAPI in breas cancer cells. Cancer Res 2006; 66: 2210-2218.

76. Fridman JS, Lowe SW. Control of apoptosis by p53. Oncogene 2003; 22: 9030-9040.

77. Robles Al, Bemmels NA, Foraker AB, Harris CC. APAF-1 is a transcriptional target of $p 53$ in DNA damage-induced apoptosis. Cancer Res 2001; 61: 6660-6664.
78. Soengas MS, Alarcon RM, Yoshida H, Giaccia AJ, Hakem R, Mak TW et al. Apaf-1 and caspase-9 in p53-dependent apoptosis and tumor inhibition. Science 1999; 284 : 156-159.

79. Moroni MC, Hickman ES, Lazzerini-Denchi E, Caprara G, Colli E, Cecconi F et al. Apaf-1 is a transcriptional target for E2F and p53. Nat Cell Biol 2001; 3: 552-558.

80. Furukawa $\mathrm{Y}$, Nishimura N, Furukawa $\mathrm{Y}$, Satoh $\mathrm{M}$, Endo $\mathrm{H}$, Iwase $\mathrm{C}$ et al. Apaf-1 is a mediator of E2F-1-induced apoptosis. J Biol Chem 2002; 277: 39760-39768.

81. Scott CL, Schuler M, Marsden VS, Egle A, Pellegrini M, Nesic D et al. Apaf-1 and caspase- 9 do not act as tumor suppressors in myc-induced lymphomagenesis or mouse embryo fibroblast transformation. J Cell Biol 2004; 164: 89-96.

82. Soengas M, Capodieci P, Polsky D, Mora J, Esteller M, Opitz-Araya X et al. Inactivation of the apoptosis effector Apaf-1 in malignant melanoma. Nature 2001; 409: 207-211.

83. Dai DL, Martinka M, Bush JA, Li G. Reduced Apaf-1 expression in human cutaneous melanomas. Br J Cancer 2004; 91: 1089-1095.

84. Zanon M, Piris A, Bersani I, Vegetti C, Molla A, Scarito A et al. Apoptotic proteaseactivating factor- 1 expression is dispensable for response of human melanoma cells to distinct proapoptotic agents. Cancer Res 2004; 64: 7386-7394.

85. Fu WN, Bertoni F, Kelsey SM, McElwaine SM, Cotter FE, Newland AC et al. Role of DNA methylation in the suppression of Apaf-1 protein in human leukaemia. Oncogene 2003; 22: $451-455$.

86. Watanabe $\mathrm{T}$, Hirota $\mathrm{Y}$, Arakawa $\mathrm{Y}$, Fujisawa $\mathrm{H}$, Tachibana $\mathrm{O}$, Hasegawa $\mathrm{M}$ et al. Frequent LOH at chromosome 12q22-23 and Apaf-1 inactivation in glioblastoma. Brain Pathol 2003; 13: 431-439.

87. Leo C, Horn LC, Rauscher C, Hentschel B, Richter CE, Schutz A et al. Lack of apoptotic protease-activating factor-1 expression and resistance to hypoxia-induced apoptosis in cervical cancer. Clin Cancer Res 2007; 13: 1149-1153.

88. Zlobec I, Minoo P, Baker K, Haegert D, Khetani K, Tornillo L et al. Loss of APAF-1 expression is associated with tumour progression and adverse prognosis in colorectal cancer. Eur J Cancer 2007; 43: 1101-1107.

89. Sturm I, Bosanquet AG, Radetzki S, Hummel M, Dorken B, Daniel PT. Silencing of APAF-1 in B-CLL results in poor prognosis in the case of concomitant p53 mutation. Int $\mathrm{J}$ Cancer 2006; 118: 2329-2336.

90. Furukawa $\mathrm{Y}$, Sutheesophon $\mathrm{K}$, Wada T, Nishimura M, Saito $\mathrm{Y}$, Ishii $\mathrm{H}$ et al. Methylation silencing of the Apaf-1 gene in acute leukemia. Mol Cancer Res 2005; 3: 325-334

91. Wolf BB, Schuler M, Li W, Eggers-Sedlet B, Lee W, Tailor P et al. Defective cytochrome $c$-dependent caspase activation in ovarian cancer cell lines due to diminished or absent apoptotic protease-activating factor-1 activity. J Biol Chem 2001; 276: 34244-34251.

92. Liu JR, Opipari AW, Tan L, Jiang Y, Zhang Y, Tang $\mathrm{H}$ et al. Dysfunctional apoptosome activation in ovarian cancer: implications for chemoresistance. Cancer Res 2002; 62 : 924-931.

93. Krepela E, Prochazka J, Liul X, Fiala P, Kinkor Z. Increased expression of Apaf-1 and procaspase-3 and the functionality of intrinsic apoptosis apparatus in non-small cell lung carcinoma. Biol Chem 2004; 385: 153-168.

94. Piddubnyak V, Rigou P, Michel L, Rain JC, Geneste O, Wolkenstein P et al. Positive regulation of apoptosis by HCA66, a new Apaf-1-interacting protein, and its putative role in the physiopathology of NF1 microdeletion syndrome patients. Cell Death Differ 2007; 14: $1222-1233$

95. Fadeel B, Zhivotovsky B, Orrenius S. All along the watchtower: on the regulation of apoptosis regulators. FASEB J 1999; 13: 1647-1657.

96. Wright CW, Duckett CS. Reawakening the cellular death program in neoplasia through the therapeutic blockade of IAP function. J Clin Invest 2005; 115: 2673-2678.

97. Ambrosini G, Adida C, Altieri DC. A novel antiapoptosis gene, survivin, expressed in cancer and lymphoma. Nat Med 1997; 3: 917-921.

98. Fulda S, Wick W, Weller M, Debatin KM. Smac agonists sensitize for Apo2L/TRAIL- or anticancer drug-induced apoptosis and induce regression of malignant glioma in vivo. Nat Med 2002; 8: 808-815

99. Yang L, Mashima T, Sato S, Mochizuki M, Sakamoto H, Yamori T et al. Predominant suppression of apoptosome by inhibitor of apoptosis protein in non-small cell lung cancer $\mathrm{H} 460$ cells: therapeutic effect of a novel polyarginine-conjugated Smac peptide. Cancer Res 2003; 63: 831-837.

100. Sun Y, Ottosson A, Pervaiz S, Fadeel B. Smac-mediated sensitization of human B lymphoma cells to staurosporine- and lactacystin-triggered apoptosis is apoptosomedependent. Leukemia 2007; 21: 1035-1043.

101. Reed JC. Drug insight: cancer therapy strategies based on restoration of endogenous cell death mechanisms. Nat Clin Pract Oncol 2006; 3: 388-398.

102. Webb A, Cunningham D, Cotter F, Clarke PA, Di Stefano F, Ross P et al. BCL-2 antisense therapy in patients with non-Hodgkin lymphoma. Lancet 1997; 349: 1137-1141.

103. Taylor JK, Zhang QQ, Wyatt JR, Dean NM. Induction of endogenous Bcl- $X_{S}$ through the control of Bcl-X pre-mRNA splicing by antisense oligonucleotides. Nat Biotechnol 1999; 17: $1097-1100$.

104. Walensky LD, Kung AL, Escher I, Malia TJ, Barbuto S, Wright RD et al. Activation of apoptosis in vivo by a hydrocarbon-stapled BH3 helix. Science 2004; 305: 1466-1470.

105. Oltersdorf T, Elmore SW, Shoemaker AR, Armstrong RC, Augeri DJ, Belli BA et al. An inhibitor of Bcl-2 family proteins induces regression of solid tumours. Nature 2005; 435: $677-681$. 
106. Mashima T, Oh-hara T, Sato S, Mochizuki M, Sugimoto Y, Yamazaki K et al. p53defective tumors with a functional apoptosome-mediated pathway: a new therapeutic target. J Natl Cancer Inst 2005; 97: 765-777.

107. Nguyen JT, Wells JA. Direct activation of the apoptosis machinery as a mechanism to target cancer cells. Proc Natl Acad Sci USA 2003; 100: 7533-7538.

108. Wang $S$, Yan-Neale $Y$, Cai R, Alimov I, Cohen D. Activation of mitochondrial pathway is crucial for tumor selective induction of apoptosis by LAQ824. Cell Cycle 2006; 5: 1662-1668.

109. Hu Y, Cherton-Horvat G, Dragowska V, Baird S, Korneluk RG, Durkin JP et al. Antisense oligonucleotides targeting XIAP induce apoptosis and enhance chemotherapeutic activity against human lung cancer cells in vitro and in vivo. Clin Cancer Res 2003; 9: 2826-2836.

110. Schimmer AD, Welsh K, Pinilla C, Wang Z, Krajewska M, Bonneau MJ et al. Smallmolecule antagonists of apoptosis suppressor XIAP exhibit broad antitumor activity. Cancer Cell 2004; 5: 25-35.
111. Mesri M, Wall NR, Li J, Kim RW, Altieri DC. Cancer gene therapy using a survivin mutant adenovirus. J Clin Invest 2001; 108: 981-990

112. Plescia J, Salz W, Xia F, Pennati M, Zaffaroni N, Daidone MJ et al. Rational design of shepherdin, a novel anticancer agent. Cancer Cell 2005; 7: 457-468.

113. Li L, Thomas RM, Suzuki H, De Brabander JK, Wang X, Harran PG. A small molecule Smac mimic potentiates TRAIL- and TNF $\alpha$-mediated cell death. Science 2004; 305 1471-1474.

114. Leaman DW, Chawla-Sarkar M, Vyas K, Reheman M, Tamai K, Toji S et al. Identification of X-linked inhibitor of apoptosis-associated factor-1 as an interferon-stimulated gene that augments TRAIL Apo2L-induced apoptosis. J Biol Chem 2002; 277: 28504 28511.

115. Fischer U, Schulze-Osthoff K. Apoptosis-based therapies and drug targets. Cell Death Differ 2005; 12 (Suppl 1): 942-961. 